\title{
LA MINERÍA MEXICANA EN EL CONTEXTO INTERNACIONAL
}

Darcy Tetreault

Unidad Académica en Estudios del Desarrollo, UAZ

\begin{abstract}
Este artículo aborda las causas estructurales de los conflictos socioambientales en la minería de México. A diferencia de otros países latinoamericanos, donde el Estado ha logrado imponer mayores controles regulatorios, impuestos y regalías a empresas extranjeras, el gobierno mexicano ha buscado atraer inversión extranjera directa (IED) al sector a través de la desregulación y exención de impuestos. De esta manera, ha llegado a ser el primer receptor de IED en la región para la exploración minera, con las empresas canadienses como punteras. La tecnología empleada por estas empresas permite la explotación rentable de yacimientos de baja ley, al "externalizar" los costos ambientales y sociales. Estos costos son pagados, principalmente, por las comunidades campesinas e indígenas, cuyos medios de vida, salud, paisajes culturales y territorios son amenazados por la minería.
\end{abstract}

$\mathrm{E}$ $\mathrm{n}$ los últimos años se han analizado conflictos en torno a la minería como parte de una discusión más amplia sobre las tendencias recientes de las industrias extractivas en América Latina. ${ }^{1}$ Desde la llegada del nuevo milenio, la región ha visto un repunte en la producción de bienes primarios, lo que Veltmeyer llama "la reprimarización de las economías de América Latina", ${ }^{2}$ con referencia al papel que jugaron estos países en la economía internacional antes de que tuviera lugar una industrialización acelerada en la segunda mitad del siglo $\mathrm{XX}$. Desde esta perspectiva, las políticas de ajuste estructural de las décadas de los ochenta y noventa prepararon el terreno para la dominación extranjera en la extracción de recursos en toda la región, con excepciones y matices, por ejemplo, donde los gobiernos han mantenido o recobrado el control de sectores estratégicos a través de empresas estatales (Petrobras en Brasil, Codelco en Chile, PDVSA en Venezuela, Pemex en México, etcétera). Más aún, donde han accedido al poder gobiernos progresistas, el Estado ha impuesto mayores controles regulatorios, impuestos y regalías a empresas extranjeras. Un ejemplo claro de esto es el sector minero de Bolivia. Ésta es la esencia del llamado "nuevo extractivismo". ${ }^{3}$ Como sugiere Veltmeyer, al final de cuentas se trata de lograr un acuerdo entre el Estado y el capital más favorable para el primero, con la afirmación de que los ingresos públicos derivados de la explotación de recursos naturales se usarán para el desarrollo social. ${ }^{4} \mathrm{El}$ sector minero mexicano es una excepción en tanto que el gobierno federal ha buscado atraer inversión extranjera directa (IED) a través de la desregulación y las exenciones de impuestos.

Existe un consenso general en el sentido de que el auge en bienes primarios en América Latina ha sido impulsado por el aumento en la demanda de metales, petróleo y productos agrícolas a nivel global. El consumismo de los ricos y las clases medias en todo el mundo, en particular en el Norte global, estimula esta demanda. ${ }^{5}$ Desde otro ángulo, China y, en menor medida, India - con alrededor de un tercio de la población mundial y con economías que están experimentando un desarrollo rápido de su infraestructura-, han ejercido una presión creciente sobre los suministros globales de materiales y energía. Igualmente, en el contexto de la última crisis financiera y económica, el precio del oro y de otros metales preciosos se ha disparado conforme especuladores buscan un refugio para su capital monetario. En estas circunstancias, empresas mineras, tanto estatales como transnacionales privadas, han gozado de ganancias extraordinarias. De acuerdo con Gudynas, secretario ejecutivo del Centro Latino Americano de Ecología Social (CLAES), la minería es el sector con la tasa promedio de rentabilidad más alta del mundo, ubicada en $37 \% .{ }^{6}$ En un sistema económico global orientado a la maximización de las ganancias, esto ha impulsado niveles de inversión en la exploración minera sin precedentes: 11.5 mil millones de dólares en todo el mundo en 2010, 27\% del cual se dirigió a América Latina; y dentro de la región, México es el primer receptor de IED para la exploración minera. ${ }^{7}$

En este sentido, es importante subrayar el papel de las empresas mineras canadienses, las cuales representan cerca del $40 \%$ del gasto en la exploración minera a nivel global, con 1,062 proyectos en Sudamérica y 618 en México. ${ }^{8}$ Asimismo, de las 279 empresas mineras extranjeras que operan en México, 210 son canadienses. Están encabezadas por empresas como Goldcorp, NewGold, Alamos Gold, Endeavour Silver, First Majestic Silver y Fortuna Silver Mines. También hay tres empresas mineras mexicanas gigantescas que lograron expandirse fuertemente y consolidar sus activos hacia finales de los ochenta y principios de los noventa durante la privatización en 


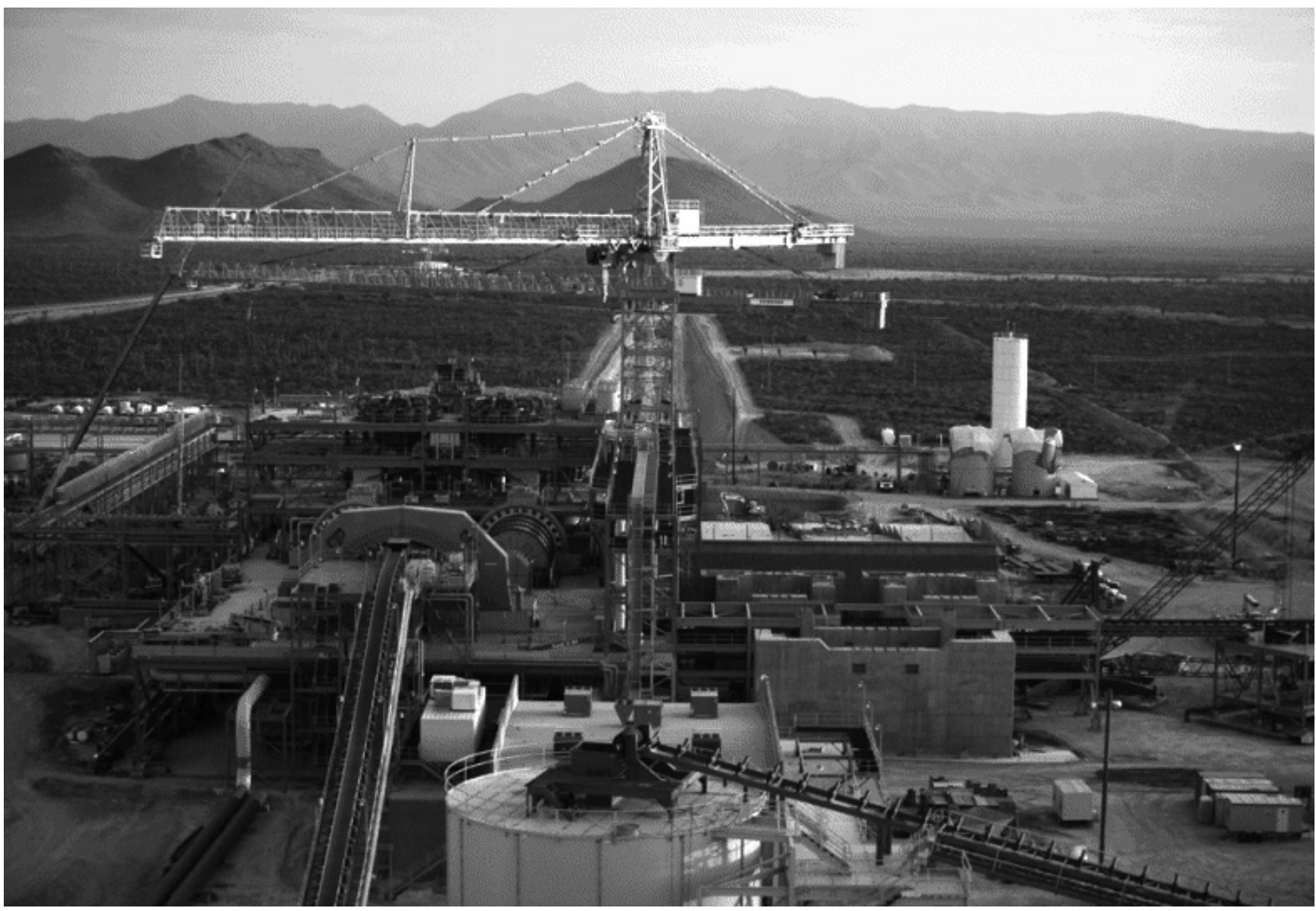

remate de empresas del sector público y de las reservas minerales nacionales: Minera Frisco, Industrias Peñoles y Grupo México. ${ }^{9}$ No causa sorpresa el hecho de que los dueños de estas empresas son, respectivamente, Carlos Slim (el hombre más rico del mundo), Alberto Bailleres (el tercer hombre más rico en México) y Germán Larrea (el cuarto más rico en México).

Los desarrollos tecnológicos en la industria minera han facilitado la exploración y han hecho económicamente factible la explotación de reservas minerales anteriormente inaccesibles. De hecho, en México y en otras partes de América Latina, las empresas mineras están volviendo a zonas que se habían agotado por métodos mineros convencionales desde mediados del siglo veinte o antes, para poder explotar yacimientos de baja ley con tecnologías de vanguardia, incluyendo la minería a cielo abierto, ${ }^{10}$ la hidrometalurgia, pirometalurgia y electrometalurgia. Estas tecnologías también han abierto nuevas fronteras en zonas donde las actividades mineras han sido insignificantes históricamente, en especial en el sur de México, donde se concentra la población indígena.

Los proyectos mineros modernos de gran escala conllevan múltiples consecuencias ambientales y sociales.
La minería a cielo abierto destruye completamente la tierra que contiene los minerales, dejando tras de sí cráteres enormes y cerros de escombros contaminados que emiten tóxicos al ambiente. Aparte de las consideraciones estéticas, esto implica la pérdida de hábitat para la fauna silvestre y, aún más importante para nuestro análisis, priva a comunidades locales de utilizar la misma tierra para la agricultura, la actividad forestal u otros propósitos. Lo que es más, se usan explosivos poderosos en la minería a cielo abierto, lo que significa que las comunidades ubicadas cerca de sitios mineros no sólo tienen que soportar mucho ruido, sino que los edificios también pueden sufrir daños estructurales. Estos son sólo algunos de los problemas que enfrentan agricultores nahuas que viven en las cercanías de la mina de Peña Colorada en la Sierra de Manantlán, así como los habitantes del Cerro de San Pedro, ubicado justo a un lado de la mina de NewGold en San Luis Potosí, sólo por dar dos ejemplos.

La lixiviación, o sea, el proceso químico a través del cual se separan los minerales del residuo mineral, presenta otros problemas, tanto para la minería a cielo abierto como para la subterránea. Los procesos de lixiviación modernos emplean grandes cantidades de agua, privando frecuen- 
temente a comunidades locales del agua que necesitan para realizar actividades agrícolas de pequeña escala. Tal es el caso de Mazapil, Zacatecas, donde recientemente Goldcorp abrió la mina de oro más grande de México. Una preocupación aún más seria es la contaminación que es el resultado casi inevitable de la aplicación de químicos altamente tóxicos durante el proceso de lixiviación, incluyendo el cianuro en el caso del oro. Finalmente, la fundición y refinación de metales consume grandes cantidades de energía y es una fuente significativa de contaminación del aire. Mientras la mayoría de las empresas mineras en México presumen algún tipo de certificación de gestión ambiental, la realidad es que las operaciones mineras contemporáneas causan destrucción ambiental masiva. ${ }^{11}$ En este tenor, la Comisión para la Cooperación Ambiental (CCA) reporta que la minería es responsable del 63\% de todas las emisiones tóxicas al suelo en América del Norte. ${ }^{12}$

Las personas más afectadas por esta destrucción ambiental son aquellas que viven en las comunidades ubicadas cerca de los sitios de minería. En México, estas comunidades tienden a ser pobladas por familias rurales pobres con estrategias económicas diversificadas que incluyen la agricultura y ganadería de pequeña escala, así como la migración laboral temporal y permanente (para algunos miembros de la familia). Las comunidades indígenas están siendo afectadas cada vez más, conforme las operaciones mineras se expanden hacia las zonas relativamente aisladas que estos grupos han ocupado desde la Conquista, las llamadas "regiones de refugio". ${ }^{13}$ Es en estas comunidades donde han sido más fuertes los movimientos de resistencia locales y, a su vez, donde la represión ha sido más brutal.

Referencias

${ }^{1}$ Véase, por ejemplo, Bebbington, Anthony; Leonith Hinojosa, Denise Humphreys Bebbington, Maria Luisa Burneo y Ximena Warnaars (2009), “Contienda y Ambigüedad: Minería y Posibilidades de Desarrollo" en Debate Agrario, no. 44, pp. 31-62; Cypher, James (2010), “South America's Commodities Boom. Developmental Opportunity or Path Dependent Reversion?" en Canadian Journal of Development Studies, vol. XXX, no. 3-4, pp. 635-662; Delgado, Gian Carlo (2012), “América Latina: Extractivismo, fronteras ecológicas y geopolítica de los recursos" en América Latina en movimiento, no. 473, pp. 1-4; Gudynas, Eduardo (2010), "El nuevo extractivismo del siglo XXI. Diez tesis sobre el extractivismo bajo el progresismo sudamericano actual" en Revista Memoria, Mayo/ Junio, no. 242-243, pp. 12-17/ 24-30.

${ }^{2}$ Veltmeyer, Henry (2012), “The Natural Resource Dynamics of Post-Neoliberalism in Latin America: New Developmentalism or Extractivist Imperialism?", documento de trabajo inédito, Unidad Académica en Estudios del Desarrollo, Zacatecas, UAZ.
${ }^{3}$ Gudynas (2010).

${ }^{4}$ Veltemeyer (2012).

${ }^{5}$ Earthworks y Oxfam América estiman que el ciudadano estadounidense promedio consume un poco más de 57 kilos diarios de minerales "nuevamente minados", es decir, minerales que no han sido reciclados. Earthworks y Oxfam America (2004), Dirty Metals. Mining, Communities and the Environment, Washington DC, Earthworks y Oxfam America.

${ }^{6}$ Eduardo Gudynas, apud. Cisnero, Fernán (2011), "Los países mineros quieren dejar de serlo", entrevista con Eduardo Gudynas, Qué Pasa, Montevideo, 9 de abril; disponible en http://www.elpais.com.uy/suplemento/quepasa/los-paises-mineros-quieren-dejar-de-serlo-/quepasa_558586_110409.html).

${ }^{7}$ CAMIMEX (Cámara Minera de México) (2011), Informe Anual 2011, México, CAMIMEX.

${ }^{8}$ Mining Association of Canada (2011), Facts and Figures of the Canadian Mining Industry; disponible en http://www.mining. ca/www/media_lib/MAC_Documents/F\&F2011-English.pdf).

${ }^{9}$ Delgado Wise, Raúl y Rubén Del Pozo Mendoza (2002), Minería, Estado y gran capital en México, México, UNAM, Centro de Investigaciones Interdisciplinarias en Ciencias y Humanidades.

${ }^{10}$ En 1944 se desarrolló la primera gran mina a cielo abierto en México, en Cananea, Sonora. Para finales del siglo, se estimaba que había en el país 1,846 grandes minas a cielo abierto (Jiménez et al., 2006: 12). Jiménez, Carolina; Pilar Huante y Emmanuel Rincón (2006), Restauración de minas superficiales en México, México, SEMARNAT.

${ }^{11}$ Earthworks y Oxfam America (2004).

${ }^{12}$ CCA (2011), En balance. Emisiones y transferencias de contaminantes en América del norte, Montreal, CCA, p. 14.

${ }^{13}$ Aguirre Beltrán, Gonzalo (1991), Obra Antropológica IX. Regiones de Refugio: El desarrollo de la comunidad y el proceso dominical en mestizoamérica, México, Fondo de Cultura Económica. 